\section{Commentary: Targeting neointimal lesions in pulmonary vein stenosis: Fact or fiction?}

\author{
Rachel D. Vanderlaan, MD, PhD
}

The hallmark of pulmonary vein stenosis (PVS) is progressive neointimal formation; however, the underlying molecular mechanisms remain largely unknown. Human histologic specimens document myofibroblast cells that are surrounded in rich extracellular matrix ${ }^{1}$ and evidence of activated tyrosine kinase receptors with immunohistochemistry, ${ }^{2}$ whereas an animal neonatal bilateral pulmonary vein banding model of PVS demonstrated a potential role for endothelial to mesenchymal transition in neointimal formation. ${ }^{3,4}$ Similar to coronary artery disease, PVS neointimal formation is likely multifactorial with different cellular processes contributing over the temporal evolution of the disease (Figure 1). Understanding these processes is paramount to allow complementary medical treatment for this disease, and the recent uptake of imatinib, bevacizumab, rapamycin, and losartan reiterate the medical community's desire to tackle this disease. ${ }^{4-6}$

In this article, Masaki and colleagues ${ }^{7}$ use an animal piglet model modified from the bilateral banding model previously used. ${ }^{3}$ Using a "cut-and-sew technique" to mimic conventional repair of total anomalous pulmonary venous return, the authors induce a $70 \%$ stenosis in the left lower pulmonary vein that resulted in pulmonary vein occlusion by 8 weeks. Immunohistochemistry studies identified Ki67-positive cells in the area of that stenotic anastomosis, suggesting that proliferation contributes to the early anastomotic lesion. Additional markers denoted myofibroblasts potentially derived from smooth muscle cells and early activation of the mammalian target of rapamycin signaling pathway. To target these proliferating cells, the authors used rapamycin-eluting films that

\footnotetext{
From the Division of Cardiovascular Surgery, Hospital for Sick Children, Toronto, Ontario, Canada.

Disclosures: Author has nothing to disclose with regard to commercial support.

Received for publication Feb 4, 2020; accepted for publication Feb 4, 2020; available ahead of print Feb 14, 2020.

Address for reprints: Rachel D. Vanderlaan, MD, PhD, Hospital for Sick Children, 555 University Ave, Room 1525 Hill Wing, Toronto, Ontario, M5G 1X8 (E-mail: rachel.vanderlaan@sickkids.ca).

J Thorac Cardiovasc Surg 2020;160:794-5 0022-5223/ $\$ 36.00$

Crown Copyright $(2020$ Published by Elsevier Inc. on behalf of The American Association for Thoracic Surgery

https://doi.org/10.1016/j.jtcvs.2020.02.021
}

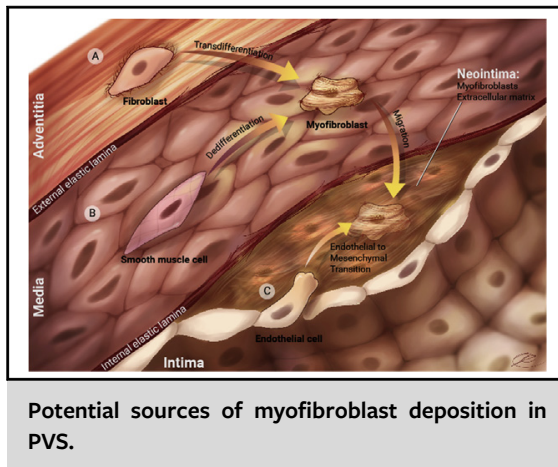

CENTRAL MESSAGE

Neointimal formation is the hallmark of PVS. Understanding the molecular mechanisms underlying myofibroblast deposition will help design effective novel therapies.

were applied to the external surface of the anastomosis. In their in vivo model, release of rapamycin peaked at 2 weeks and was completed by 4 weeks.

Although the data are largely hindered by a study design that limits examination of the important 4-week time point and lack of double staining to confirm signaling in proliferating cells, the concept of local drug delivery is intriguing. Use of drug-eluting stents and drug-eluting balloons is commonplace in the adult coronary literature, with case reports and retrospective series increasingly populating the PVS literature. ${ }^{89}$ The concept of an externally applied scaffold or film at the time of surgical intervention offers some advantages: targeted local delivery and avoidance of potential systemic side effects. It also represents an opportunity to potentially tailor drug delivery outside of commercially available drug-eluting balloons and stents.

The study demonstrated a transient delay in pulmonary vein occlusion until 3 to 4 weeks, which coincides with drug-release data showing minimal to no drug delivery after the 4-week mark. Although the delayed progression is promising, there are unanswered questions related to the study. Given the off-label use of oral rapamycin, it is unclear what the effectiveness of the drug-eluting film delivery is compared with systemic delivery over the same time course. In addition, data from this and other studies suggest less of a role for proliferation as lesions mature, begging the question as to whether the inevitable pulmonary vein occlusion that occurs is a result of inadequate drug delivery after 


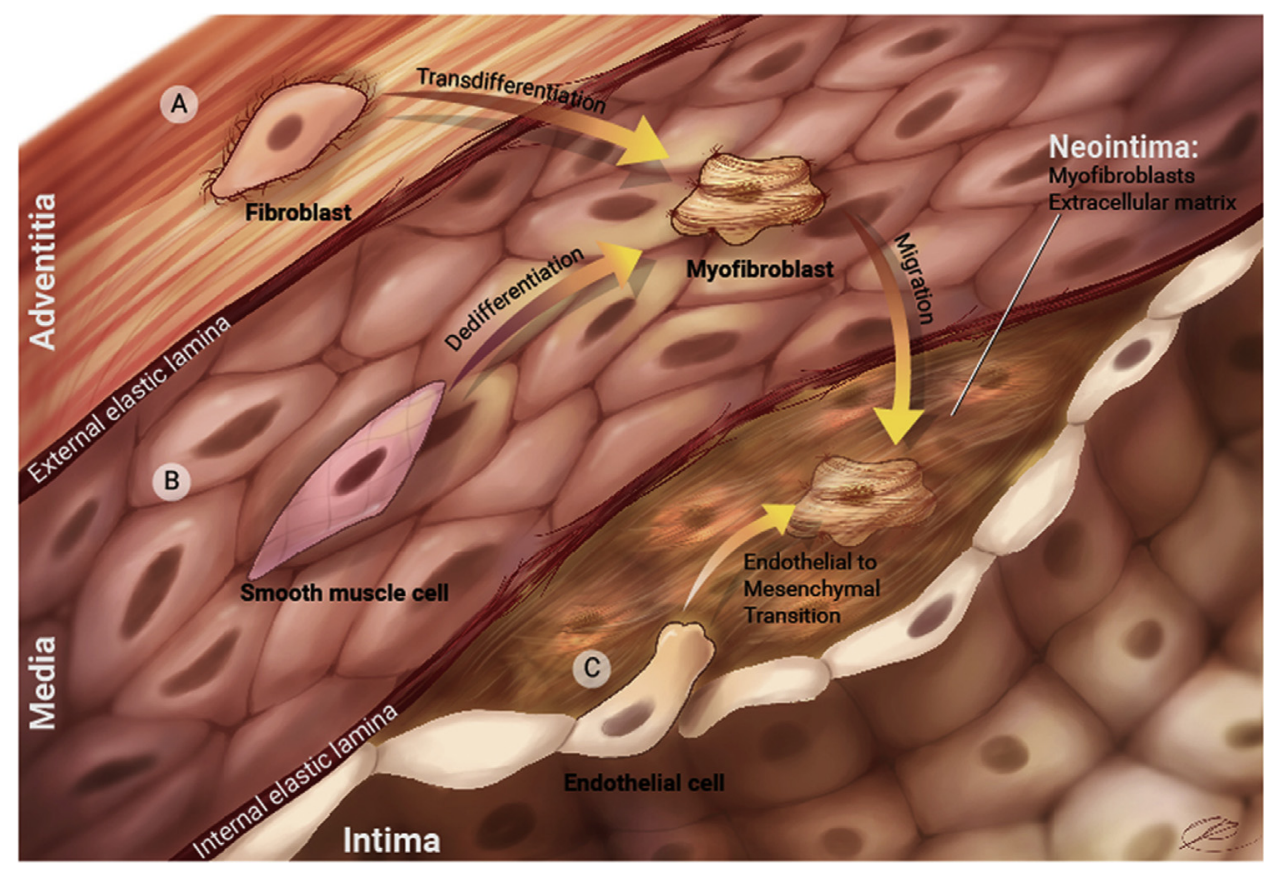

FIGURE 1. Potential sources of myofibroblast deposition in PVS include (A) transdifferentiation of fibroblasts, (B) de-differentiation of smooth muscle cells, and (C) endothelial to mesenchymal transition. Permission from R.D. Vanderlaan, PVS Network (www.PVSNetwork.org).

3 to 4 weeks or of ineffective targeting of an alternative molecular driver for PVS.

Further research focused on understanding the molecular mechanisms underlying both the etiology and the progressive neointimal lesion formation is essential. Given the complex nature of neointimal lesion formation, a multimodal approach will likely be needed. Although this study requires further follow-up studies to address outstanding limitations, external drug-eluting films are an interesting potential addition to the armamentarium clinicians may have one day to address progressive PVS.

\section{References}

1. Sadr IM, Tan PE, Kieran MW, Jenkins KJ. Mechanism of pulmonary vein stenosis in infants with normally connected veins. Am J Cardiol. 2000;86:577-9.A10.

2. Riedlinger WF, Juraszek AL, Jenkins KJ, Nugent AW, Balasubramanian S, Calicchio ML, et al. Pulmonary vein stenosis: expression of receptor tyrosine kinases by lesional cells. Cardiovasc Pathol. 2006;15:91-9.
3. Kato H, Fu YY, Zhu J, Wang L, Aafaqi S, Rahkonen O, et al. Pulmonary vein stenosis and the pathophysiology of "upstream" pulmonary veins. J Thorac Cardiovasc Surg. 2014;148:245-53.

4. Zhu J, Ide H, Fu YY, Teichert AM, Kato H, Weisel RD, et al. Losartan ameliorates "upstream" pulmonary vein vasculopathy in a piglet model of pulmonary vein stenosis. J Thorac Cardiovasc Surg. 2014;148:2550-7.

5. Callahan R, Kieran MW, Baird CW, Colan SD, Gauvreau K, Ireland CM, et al. Adjunct targeted biologic inhibition agents to treat aggressive multivessel intraluminal pediatric pulmonary vein stenosis. J Pediatr. 2018;198:29-35.e5

6. Callahan R, Esch JJ, Wang G, Ireland CM, Gauvreau K, Jenkins KJ. Systemic sirolimus to prevent in-stent stenosis in pediatric pulmonary vein stenosis. Pediatr Cardiol. November 12, 2019 [Epub ahead of print].

7. Masaki N, Adachi O, Katahira S, Saiki Y, Horii A, Kawamoto S, et al. Progression of vascular remodeling in pulmonary vein obstruction. J Thorac Cardiovasc Surg. 2020;160:777-90.e5.

8. Müller MJ, Krause U, Paul T, Schneider HE. Serum levels after everolimus-stent implantation and paclitaxel-balloon angioplasty in an infant with recurrent pulmonary vein obstruction after repaired total anomalous pulmonary venous connection. Pediatr Cardiol. 2011;32:1036-9.

9. Cory MJ, Ooi YK, Kelleman MS, Vincent RN, Kim DW, Petit CJ. Reintervention is associated with improved survival in pediatric patients with pulmonary vein stenosis. JACC Cardiovasc Interv. 2017;10:1788-98. 